\title{
SALMONELLA AND ANTIMICROBIAL RESISTANCE IN AN ANIMAL-BASED AGRICULTURE RIVER SYSTEM
}

\author{
Palhares, J.C.P. ${ }^{* 1}$; Kich, J.D. ${ }^{2}$; Berno-Lazzarin L.G ${ }^{3}$; Gugel A. L ${ }^{4}$; Biesus, L.L. ${ }^{5}$; Bessa, M.C. ${ }^{6}$ \\ ${ }^{1}$ Embrapa Cattle Southeast, Sao Carlos-SP-Brasil. \\ e-mail:palhares@cppse.embrapa.br \\ ${ }^{2,5}$ Embrapa Swine and Poultry, Concordia-SC-Brasil. \\ ${ }^{3,4}$ CNPq PIBIC-Contestado University- Concordia-SC \\ ${ }^{6}$ Faculty of Bioscience - PUC-RS, Porto Alegre-RS-Brasil.
}

\begin{abstract}
The aim of this study was to examine the Salmonella serovars and antimicrobial resistance within an animal-based agriculture river system. The study area consisted of a 1,345 ha sub-basin at the upper Pinhal River catchment. Pinhal River is located in Concordia, Santa Catarina, Brazil. The sub-basin is a typical agricultural watershed. Salmonella was isolated from 241 samples (62\%), resulting in 324 isolates. The most number of Salmonella sp. occurred in samples from sites associated with high stoking density animal unit per hectare area. It was possible to demonstrate the variability of serovars in the study area; 30 different serovars were found and at least 11 of them by monitoring the site. Among 180 isolates submitted to an antimicrobial susceptibility test, $50.5 \%$ were susceptible to all 21 antimicrobials tested, and 54 different profiles were found. In the current study $49.5 \%$ of the tested isolates were resistant in at least one antimicrobial, and multi-resistance occurred in $18 \%$ of isolates. Conduct studies that evaluate the detection of antimicrobial resistance in microorganisms of public interest and in surface water sources of catchments characterized by intensive animal production will assist communities, society and governments in decision-making.
\end{abstract}

Key words: antimicrobial resistance, dairy, pig, poultry, salmonella.

\section{INTRODUCTION}

In order to ensure responsible and cautious use of antimicrobials in livestock and veterinary medicine, and to monitor the emergence of antimicrobial resistance, the major livestock-producing countries have established their own national monitoring system. Much of the work that led to these conclusions focused on resistance transfer through the food supply. However, resistance might also migrate away from operations via water (Peak et al. 2007). In Brazil antimicrobials are used as growth promoters in swine and poultry production. Dairies just use antimicrobial as therapeutic or prevention-prophylaxis.

Salmonella is a reservoir of antibiotic multi-resistence genes (Duijkeren et al., 2003). A high percentage of antibiotic-resistant Salmonella strains from swine production has been demonstrated in Brazil. Kich et al. (2011) found 83\% (475/572) of Salmonella strains resistant to at least one antimicrobial; 43\% (246/572) were resistant to four or more antimicrobials and considered multi-resistant.

The growing consumption of animal products in developing countries demands a proportional increase in animal production. To respond to this demand, using antimicrobials prudently, a reconsideration of the production practices taking account of antimicrobial resistance is needed.

The aim of this study was to examine the Salmonella serovars and antimicrobial resistance within an animal-based agriculture river system. This study will contribute to our understanding of the relationship between livestock and environmental quality, and human and animal health. It can also collaborate with government and agencies to establish polices for antimicrobial use in animal production and the environment. 


\section{IIISIGER \\ III INTERNATIONAL SYMPOSIUM ON \\ AGRICULTURAL AND AGROINDUSTRIAL WASTE MANAGEMENT \\ 12-14 MARCH 2013 - SAO PEDRO - SP}

\section{MATERIAL AND METHODS}

The study area consisted of a 1,345 ha sub-basin at the upper Pinhal River catchment. Pinhal River is located in Concordia, Santa Catarina, Brazil. The Pinhal sub-basin is a typical agricultural watershed. The area is predominantly agricultural, with high dairy cow, poultry and pig stocking densities with a large proportion of area devoted to corn, pastures and forage crops.

Eight monitoring sites were selected and monitored monthly, from October 2006 to October 2010. The description of each site is presented in Palhares et al. (2012).

A subset of 180 Salmonella isolates was profiled according to susceptibility-resistance guidelines (CLSI, 2005). The following antimicrobial agents were evaluated: naladixic acid (NAL), $30 \mu \mathrm{g}$; amoxicillin/clavulanic acid (AMC), 20/10 ug, amikacin (AMI), $30 \mu \mathrm{g}$; ampicillin (AMP) 10 $\mu \mathrm{g}$; kanamycin (K), $30 \mu \mathrm{g}$; cephalothin (CF), $30 \mu \mathrm{g}$; ceftazidime (CAZ), $30 \mu \mathrm{g}$; ceftiofur (CEF), $30 \mu \mathrm{g}$; ciprofloxacin (CIP), $5 \mu \mathrm{g}$; chloramphenicol (CHL), $30 \mu \mathrm{g}$; colistin $(\mathrm{CL}), 10 \mu \mathrm{g}$; doxycycline (DX), $30 \mu \mathrm{g}$; enrofloxacin (ENR), $5 \mu \mathrm{g}$; streptomycin (STR), $10 \mu \mathrm{g}$; florfenicol (FLO), $30 \mu \mathrm{g}$; gentamicin (GEN), $10 \mu \mathrm{g}$; neomycin (NEO), $30 \mu \mathrm{g}$; norfloxacin (NOR), $10 \mu \mathrm{g}$; sulfametazol+trimethoprim (SXT), 1.25/23.75 $\mathrm{gg}$; tetracycline (TET), $30 \mu \mathrm{g}$; trimethoprim (TMP), $5 \mu \mathrm{g}$. Escherichia coli ATCC 25922 was used as a control strain of known antibiotic susceptibility (CLSI, 2008).

\section{RESULTS AND DISCUSSION}

A total of 384 samples were collected monthly over four consecutive years. Salmonella was isolated from 241 samples (62\%), resulting in 324 isolates. The greatest number of Salmonella positive samples occurred in sites associated with high animal density. Comparing site 1 with other catchment areas, it had the lowest count 23/48 (48\%) of Salmonella positive samples. This was an unique monitoring site without swine and poultry production; the local area has a river open to pasturing dairy cows. Site 2 does not have economic activity; the forest was preserved in agreement with the Brazilian environmental law. The number of positives can be related to contamination from an adjacent site (1) and/or the presence of wildlife.

The identical serovar from the same sample was considered a duplicate and counted once, resulting in 227 Salmonella enterica enterica (Figure 1). The subspecies Diarizonae and Houtenae were found each once. From all isolates, 30 different serovars were distributed over the sampled area. This demonstrated the high variability of the organism in this agricultural watershed.

The distribution of susceptibility/resistance of 180 Salmonella isolates is demonstrated in the Table 1 . More than fifty percent $(50.5 \%)$ were susceptible to all 21 antimicrobials tested and 54 different profiles were found. In the current study $49.5 \%$ of the isolates were resistant to at least one antimicrobial and multi-resistance (resistance to three or more classes of antimicrobials) occurred in $18 \%$ of the isolates. Watabe et al. (2003) examined the prevalence and resistance of Salmonella in pig waste, $34.6 \%$ and $7.7 \%$ of isolates were resistant to three and to four antimicrobial, respectively.

More than $10 \%$ of isolates were resistant to ampicillin, doxycycline, naladixic acid, neomycin, kanamycin, and tetracycline, with the last two presenting the highest resistance, $21.1 \%$ and $13.8 \%$, respectively. Marrero-Ortiz et al. (2012) identified and characterized antimicrobial resistance in Salmonella obtained from dairy fecal samples. They reported $42 \%$ of isolates were resistant to tetracycline and $17 \%$ resistant to kanamycin.

The important pent-resistance profile (ampicillin, chloramphenicol, streptomycin, sulfizoxazole and tetracycline), found in porcine Salmonella in many countries, was not observed in the present study, in agreement with previous investigations failing to identify this resistance pattern in the same region (Bessa et al., 2007; Kich et al. 2011). 


\section{IIISIGER I I \\ III INTERNATIONAL SYMPOSIUM ON \\ AGRICULTURAL AND AGROINDUSTRIAL WASTE MANAGEMENT \\ 12-14 MARCH 2013 - SAO PEDRO - SP}

\section{CONCLUSION}

The present and future for animal production are: high animal density per area, reduced soil for manure use as fertilizer, high dependence on antibiotics by production systems, and conflicts over water use. Investigations of antibiotic resistance in microorganisms of public health interest and in surface water catchments sources characterized by intensive animal production will assist communities, society and governments in decision-making.

\section{REFERENCES}

Bessa,M.C.; Michael,G.B.; Canu,N.; Canal,C.W.;Cardoso,M.; Rabsch,W.; Rubino,S. 2007. Phenotypic and genetic characterization of Salmonella enterica subsp. enterica serovar Typhimurium isolated from pigs in Rio Grande do Sul, Brazil. Research in veterinary science, dec;83(3):302-10.

CDC. Salmonella surveillance: Annual summary, 2004. Atlanta, GA: The Centers for Disease Control and Prevention. 2005.

CDC. Surveillance for Foodborne Disease Outbreaks - United States, 2008. Disponible:

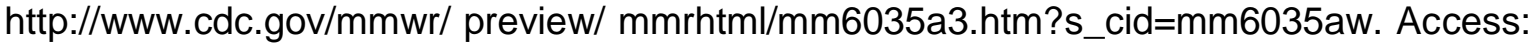
19 nov. de 2011

Duijkeren, E.; et al. Antimicrobial susceptibilities of Salmonella strains isolated from humans, cattle, pigs and chickens in The Netherlands from 1984 to 2001. Journal of Clinical Microbiology, v.41, p.3574-3578. 2003.

Kich, J.D.; et al. Prevalence, distribution, and molecular characterization of Salmonella recovered from swine finishing herds and a slaughter facility in Santa Catarina, Brazil. International Journal of Food Microbiology, v.151, p.307-313, 2011.

Palhares, J.C.P. et al. Evaluation of environmental adjustment contract for pig production in Pinhal river sub-basin. Ambiente \& Agua, v.6, p.86-97. 2011

Peak, N. et al. Abundance of six tetracycline resistance genes in wastewater lagoons at cattle feedlots with different antibiotic use strategies. Environmental Microbiology, v.9, p.143-151. 2007.

Marrero-Ortiz, R. et al. Genetic characterization of antimicrobial resistance in Salmonella enterica serovars isolated from dairy cattle in Wisconsin. Food Research International, v.45, p.962-967. 2012.

Watabe, M., et al. Prevalence of bacterial faecal pathogens in separated and unseparated stored pig slurry. Lett. Appl. Microbiol., v.36, p.208-212. 2003. 
Figure 1. Occurrence of Salmonella serovars in four years of Pinhal river monitoring.

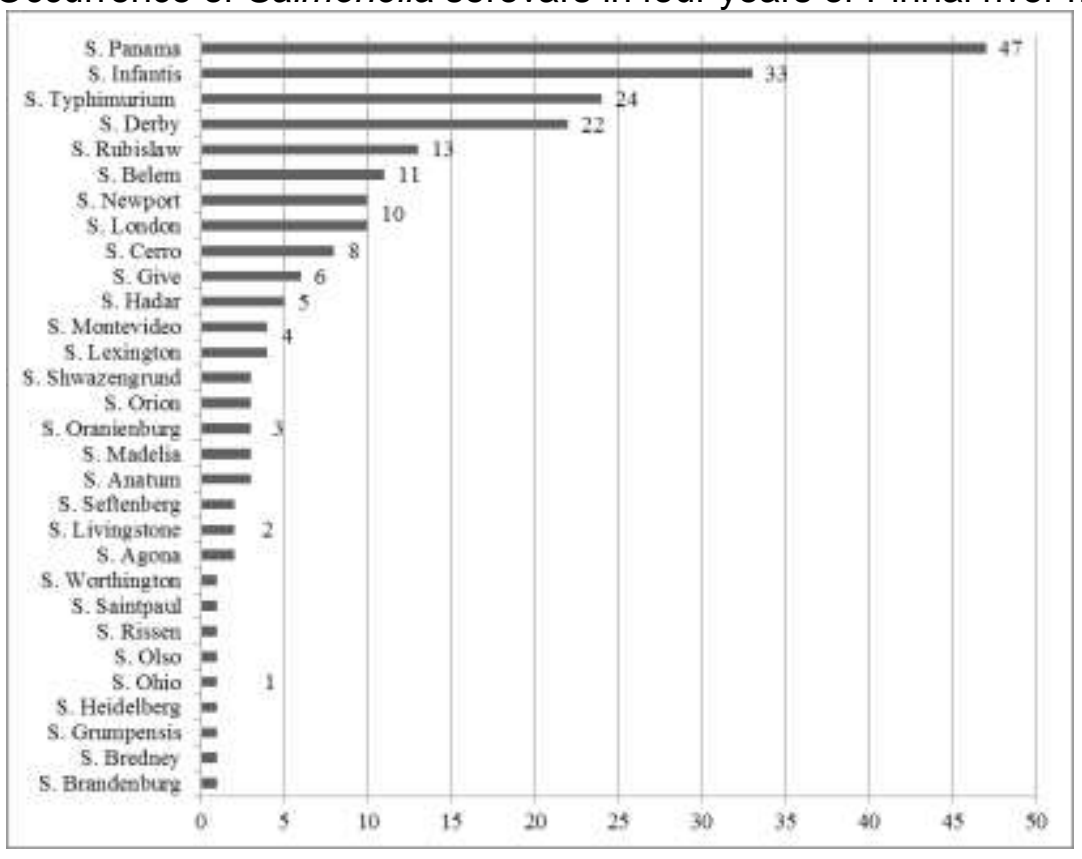

Table 1. Distribution of susceptibility/resistence of 180 Salmonella isolates from Pinhal river.

\begin{tabular}{ccccccc}
\hline Antimicrobial & \multicolumn{2}{c}{ Susceptibility } & \multicolumn{2}{c}{ Intermediate } & \multicolumn{2}{c}{ Resistance } \\
\hline AMIKACIN (AMI) & $\mathbf{N}$ & $\%$ & $\mathbf{N}$ & $\%$ & $\mathbf{N}$ & $\%$ \\
\hline AMOXICILLIN/CLAVULANIC ACID (AMC) & 177 & 98.33 & 1 & 0.56 & 2 & 1.11 \\
AMPICILLIN (AMP) & 166 & 92.22 & 3 & 1.67 & 11 & 6.11 \\
CEFTAZIDIME (CAZ) & 174 & 79.44 & 16 & 8.89 & 21 & 11.67 \\
CEFTIOFUR (CEF) & 176 & 97.78 & 2 & 1.11 & 2 & 1.11 \\
CEPHALOTHIN (CF) & 169 & 93.89 & & 0.00 & 11 & 6.11 \\
CHLORAMPHENICOL (CHL) & 172 & 95.56 & 2 & 1.11 & 6 & 3.33 \\
CIPROFLOXACIN (CIP) & 174 & 96.67 & 5 & 2.78 & 1 & 0.56 \\
COLISTIN (CL) & 172 & 95.56 & 4 & 2.22 & 4 & 2.22 \\
DOXYCYCLINE (DX) & 152 & 84.44 & 4 & 2.22 & 24 & 13.33 \\
ENROFLOXACIN (ENR) & 178 & 98.89 & 1 & 0.56 & 1 & 0.56 \\
FLORFENICOL (FLO) & 176 & 97.78 & 1 & 0.56 & 3 & 1.67 \\
GENTAMICIN (GEN) & 171 & 95.00 & & 0.00 & 9 & 5.00 \\
KANAMYCIN (K) & 124 & 68.89 & 18 & 10.00 & 38 & 21.11 \\
NALADIXIC ACID (NAL) & 153 & 85.00 & 7 & 3.89 & 20 & 11.11 \\
NEOMYCIN (NEO) & 16 & 8.89 & 142 & 78.89 & 22 & 12.22 \\
NORFLOXACIN (NOR) & 173 & 96.11 & 2 & 1.11 & 5 & 2.78 \\
STREPTOMYCIN (STR) & 176 & 97.78 & 2 & 1.11 & 4 & 2.22 \\
TETRACYCLINE (TET) & 171 & 95.00 & 5 & 2.78 & 7 & 3.89 \\
TRIMETHOPRIM (TMP) & 150 & 83.33 & & 0.00 & 25 & 13.89 \\
SULFAMETAZOL+TRIMETHOPRIM (SXT) & 167 & 92.77 & & 0.00 & 12 & 6.67 \\
\hline
\end{tabular}

